\title{
ARTÍCULOS
}

\section{Parodia, intertextualidad y sátira en la narrativa policial de Lorenzo Lunar Cardedo}

\author{
Parody, Intertextuality and Satire in the Detective Stories \\ of Lorenzo Lunar Cardedo
}

\author{
Jesús Gómez-de-Tejada \\ Instituto Universitario de Estudios sobre América Latina (IEAL). Universidad de Sevilla \\ jgomezdetejada@us.es
}

\begin{abstract}
Detective fiction as parodic reformulation of genre's defining patterns has a long history in the Latin American tradition: Borges, Bioy Casares, Soriano, Levrero, Ibargüengoitia, etc. Besides, the evolution of Latin American detective genre has always been characterized by a progressive focalization in the social aspects over the detective story line which has served as a mask to depict in a critical way the flaws of the region's societies and governments. In nowadays Cuba it could be highlighted the crime narrative of parodic slant by Lorenzo Lunar Cardedo. Among the major features of Lunar Cardedo's style there are the marginal atmospheres, the stylization of popular speech, the intertextuality, the humor, the parody, and the social criticism. This article focuses on the parodic, intertextual and satiric aspects of his work, particularly discernible in the novel Proyecto en negro (2013), in which the author emphasizes - in opposition to the official discourse - the perpetuation of corrupt, chauvinist, racist, and homophobic behaviors in contemporary Cuba, while relaxing the genre formula limits in order to follow a much more irreverent path within the new Latin American detective fiction.
\end{abstract}

Keywords: Lorenzo Lunar Cardedo, Latin American Detective Novel, Neopolicial (New Detective Fiction), Cuban Literature, Satire, Parody 


\section{LORENZO LUNAR: REFERENTE DE LA LITERATURA NEOPOLICIAL CUBANA}

La narrativa de Lorenzo Lunar Cardedo (1958), nacido en Santa Clara, provincia de Cuba, está casi esencialmente ligada a la escritura policial. Su relación con esta modalidad literaria se extiende a múltiples ámbitos. A través de su librería y editorial La Piedra Lunar, es el propulsor de Fantoches, un premio de cuentos criminales iniciado en 2008. Es el coeditor, junto a Rebeca Murga, de la antología Confesiones (Nuevos cuentos policiales cubanos) (2011), donde ambos seleccionan los textos y escriben el prólogo inicial dentro del cual abordan la situación contemporánea de la narrativa breve del género en Cuba. Ha publicado un volumen de artículos teóricos titulado El que a hierro mata (apuntes sobre la literatura policial cubana) (2012), que el año anterior (2011) obtuvo el Premio de Investigación Literaria Florentino Morales. Finalmente, como autor, es el responsable de una de las series literarias policiales más reconocidas de la actual producción cubana "El barrio en llama": trilogía formada por las novelas Que en vez de infierno encuentres gloria (2003), La vida es un tango (2005) y Échame a mí la culpa (2006) -las tres obras fueron publicadas en un solo volumen, El barrio en llama, por la editorial Oriente (Santiago de Cuba) en 2014. Junto a estos títulos, es autor de las novelas Polvo en el viento (2005), Dónde estás corazón (2009) y Proyecto en negro (2013), además de los libros de cuentos De dos pingüé (2004), El lodo y la muerte (2007) y El asere ilustrado (2010).

Como ha señalado la crítica, el término neopolicial es utilizado originalmente por Paco Ignacio Taibo II en el contexto de una entrevista realizada por Juan Domingo Argüelles (1990). Con posterioridad, Leonardo Padura Fuentes se hace eco de la propuesta en su libro de ensayos titulado Modernidad, posmodernidad y novela policial (2000). Finalmente, un amplio sector de los teóricos dedicados a la producción policial hispanoamericana lo ha usado para referirse a una creación caracterizada, según Francisca Noguerol Jiménez (2006), por el fuerte lazo con la realidad, la importancia de lo social por encima del enigma, la focalización de la corrupción y la violencia del Estado como responsable último del crimen, la presencia de la cultura de masas, el protagonismo de las víctimas y de los criminales junto al de los investigadores, la recurrencia de recursos intertextuales y metaficticios, el desarrollo de argumentos de signo literario, o los desenlaces que se alejan de una solución unívoca y de una verdad única. El modelo neopolicial se desarrolla en Latinoamérica desde fines de los setenta y, especialmente, a partir de mediados de los ochenta. En Cuba, sin embargo, es más adelante, a inicios de los noventa, cuando Pasado perfecto (1991), de Padura, sitúa esta modalidad al lado de la novela policial revolucionaria iniciada en 1972.

En la producción neopolicial cubana, la crítica ha significado los nombres de Padura, de Amir Valle y del propio Lunar (Noguerol, 2006; Gewecke, 2010; García 
Talaván, 2014; Sánchez Zapatero y Martín Escribà, 2014; Uxó, 2016). De este modo, al lado de la tetralogía "Las cuatro estaciones" (1991-1998), de Padura, protagonizada por el teniente de policía habanero Mario Conde, y la serie de Valle, "Descenso a los infiernos" (2001-2008), que narra las peripecias en Centro Habana del policía Alain Bec y el viejo delincuente Alex Vargas, destaca la trilogía de Lunar ubicada en un barrio de la provincia cubana de Santa Clara. En estas tres novelas, se cuentan las singladuras del oficial de la Policía Nacional Revolucionaria (PNR), el teniente Leo Martín (Gewecke, 2010; Uxó, 2016). Antihéroe de profundas raíces suburbiales, Martín se enfrenta a la acción delictiva del zapatero y maceta Yago el Buey, convertido en contracara del investigador -derivación de la figura del profesor James Moriarty en las aventuras de Sherlock Holmes- en el enfrentamiento entre las fuerzas del orden y el crimen en las calles del suburbio. No obstante, como establecen las líneas del modelo neopolicial, la principal violencia tiene un carácter objetivo y sistémico -según la terminología acuñada por Slavoj Zizek- puesto que enraíza su origen en la corrupción de los cargos gubernamentales (Zizek, 2008, como se cita en Adriaensen y Grimberg Pla, 2012, p. 9). ${ }^{1}$ Tal y como ocurre en la novela Pasado perfecto, de Padura, los círculos cercanos del teniente protagonista ejemplifican la falsedad del expediente impoluto del cuadro político crecido desde el más bajo estrato social al amparo de la igualdad de oportunidades implantada por la Revolución cubana. En la trilogía de Lunar, Manolito el Buty, viejo amigo de la infancia y actual miembro del aparato de poder, es el responsable último de la red de intrigas y crímenes que asolan el barrio donde Martín vive en equilibrio entre el compromiso con el oficio de policía elegido y los códigos marginales de fidelidad aprendidos desde la infancia.

Entre los rasgos fundamentales de la obra de Lunar, destacan la ambientación marginal, la estilización del lenguaje popular, la intertextualidad, la parodia y el humor. Presentes en la trilogía "El barrio en llama", los dispositivos paródicos e intertextuales adquieren relieve principal en la novela Proyecto en negro -título en que se va a centrar el artículo. La escritura policial como reformulación paródica de los dispositivos definidores del género ha tenido una larga trayectoria en Hispanoamérica: Jorge Luis Borges y Adolfo Bioy Casares, Osvaldo Soriano, Mario Levrero, Jorge Ibargüengoitia, etc. Según señala Elzbieta Sklodowska, en su estudio sobre la transgresión paródica en la novela policial hispanoamericana, "la manipulación crítica de la fórmula policial puede llevar a la reducción de la fórmula (en cuanto pre-texto) a un pretexto que, a su vez, da pie a una reflexión auto-referencial y/o a una desmitificación satírica de la realidad" (1991, p. 115). Como se verá, ambos aspectos discursivos son predominantes en Proyecto en negro, de Lunar.

\footnotetext{
${ }^{1}$ Este aspecto ha sido brillantemente expresado por Taibo II al apuntar como uno de los objetivos del modelo neopolicial "[1]a batalla por encontrar el origen del crimen, la sutil relación entre los que disparan el gatillo y los que desde las alturas del sistema hacen que ese gatillo esté en movimiento continuo". (1987, p. 41)
} 
A continuación, se analizan los procedimientos paródicos y satíricos con los que Lunar configura Santa Clara, su ciudad natal, como un espacio citadino asfixiado por la corrupción y la violencia; flexibiliza los límites formularios del género; y se inscribe en los modos críticos más irreverentes del relato policial cubano e hispanoamericano. Igualmente, se hace referencia a los procedimientos intertextuales por medio de los cuales el autor subraya implícitamente su pertenencia a esta narrativa neopolicial.

\section{PARODIA DE LA NOVELA POLICIAL CLÁSICA Y DE LA NOVELA POLICIAL REVOLUCIONARIA CUBANA}

En Proyecto en negro, la parodia se fundamenta en la confluencia de numerosas vías de reescritura de la fórmula policial, no solo en su concepción general como novela de enigma o novela negra, sino también en relación al desarrollo del género en Cuba. Respecto al primer cauce, la obra de Lunar no se aleja de algunos de los mecanismos de apropiación o transculturación enumerados por Adriaensen y Grimberg Pla: concretamente, en la novela que se analiza, pueden reconocerse las transformaciones respecto al "rol asignado al detective o la solución del misterio" y "la crítica a las instituciones y al establishment [...] hasta sus últimas consecuencias [...al] romper con la expectativa, no tanto de ofrecer una solución al crimen, sino de garantizar el restablecimiento de la justicia" (2012, pp. 14-15). Lunar difumina o invierte las convencionales fronteras que sitúan a los buenos ciudadanos y a los policías en el lado del bien, y a los marginales y criminales en el lado del mal; de hecho, como se dijo, la violencia que emponzoña el espacio ficcional no es tanto la subjetiva, sino la sistémica promovida por el aparato represivo gubernamental a través de las fuerzas policiales y el discurso oficial.

En este último sentido, César Sánchez, el capitán de policía de La Ciudad de Proyecto en negro, ${ }^{2}$ es un delincuente uniformado que abusa de su posición cometiendo los delitos de prevaricación, cohecho y tráfico de influencias de modo rutinario y sin el menor atisbo de arrepentimiento. Tal caracterización cuadra con la visión del género en Latinoamérica propuesta tempranamente por Mempo Giardinelli -uno de los cultores y teóricos argentinos más destacados- en su estudio El género negro: ensayos sobre literatura policial (1984), donde, dentro de las justificaciones del arraigo de esta modalidad entre los autores de la región, apunta que estos "no sólo no admiran y aceptan menos a la fuerza policial y al poder de la justicia, sino que les

\footnotetext{
${ }^{2}$ La opción de sustituir el nombre de Santa Clara usado regularmente en sus narraciones evidencia un deseo de evitar los límites determinados por la apelación a un referente extraliterario inmediato, si bien la urbe real es fácilmente identificable por la mención de otros aspectos que le son propios: ríos, personajes históricos, lugares citadinos, edificios.
} 
temen, los cuestionan y los detestan; y [añade...] no se desaniman por eso, sino que están embistiendo contra eso" (Giardinelli, 1996, p. 263). ${ }^{3}$

La caricaturización paródica del policía protagonista de Proyecto en negro se subraya con la insistencia en una conducta volcada en lo sexual e instintivo en detrimento de todo interés por lo intelectual y racional. De este modo, la pesquisa se convierte en un obstáculo fastidioso que dilata sus conquistas extramaritales:

Ese muerto no le importaba a nadie; mucho menos debía importarle a él. // De veras había sido una injusticia suya, un vejamen a Idolidia y una falta de respeto a la mujer cubana en general, haber renunciado a cogerle el culo a esa ricura por causa de aquel muerto de séptima categoría. // César llegó a la Unidad de Policía dispuesto a cerrar el caso por falta de pruebas, por falta de interés social y hasta por falta de muerto. // Cuco Mondongo no era nadie. [...] Al cabo de dos o tres semanas nadie se acordaría del mendigo. Él debía dedicar su tiempo a cosas más importantes; Idolidia, por ejemplo. (Lunar, 2013, pp. 22-23)

La trama criminal con que Lunar envuelve a su corrupto oficial, en cierta medida, subvierte también la elaboración metafísica detectivesca con que Jorge Luis Borges parodia a su vez la novela enigma anglosajona a través del cuento "La muerte y la brújula" incluido en Ficciones (1944). Si ambas narraciones hispanoamericanas coinciden en que el seguimiento de las pistas sirve al detective tan solo para descubrir la trampa que supone su aniquilación o caída, las dos se diferencian extremadamente en los rasgos, las motivaciones y métodos característicos de sus protagonistas: la cultura y racionalidad de Erik Lonrot frente a la falta de formación y visceralidad del capitán César Sánchez.

El capitán de la policía de Santa Clara protagonista de Proyecto en negro es víctima del laberinto tejido por el Estado en torno a su figura: los rasgos predominantes de César -físico portentoso, personalidad desmesuradamente machista y homófoba, escasa racionalidad y nulo compromiso con el trabajo-, se sitúan frente a la fragilidad física, la homosexualidad, el poder inductivo y la dedicación a la labor policial de su ayudante el teniente Lázaro Andrés García. La muerte del sin techo Cuco Mondongo, muy probablemente ejecutada bajo las directrices del Gobierno, pone en marcha el aparato de poder para reemplazar una figura esencial en el proyecto de expansión del turismo de la zona. En contraposición al discurso oficial que silencia la existencia de la prostitución, el racismo y la homosexualidad en la isla, las urgencias económicas propulsan el desarrollo oficioso de una secreta y particular atracción turística: el perturbado mendigo era conocido internacionalmente por violentar

\footnotetext{
${ }^{3}$ La misma idea es desarrollada por Taibo II: "los escritores de habla hispana le tememos a la policía. Mucha seudodemocracia bárbara en nuestros países, mucha violencia contra los ciudadanos, para sentirnos a gusto con esos personajes. [...] Presisamente [sic] por ser como son nuestras sociedades, era necesaria otra novela negra, que rescatara esa forma de ver la sociedad, este temor a unas fuerzas policíacas que se volvían con harta facilidad parte esencial del crimen”. (1987, p. 37)
} 
a los locales y a los extranjeros ebrios que siguiendo sus impulsos eróticos se dejaban secuestrar en la oscuridad de las calles, atraídos por el reclamo de los encantos santaclareños publicitados - con el consentimiento tácito de las autoridades cubanasen clandestinas guías sexuales difundidas por Europa.

La resolución del crimen, lejos de condenar al asesino y restituir el orden social, se limita a castigar al corrupto capitán de policía; paradójicamente, no por delitos tan punibles como la tortura y la prevaricación, sino como consecuencia del color de la piel, circunstancia que manifiesta el racismo del coronel Hernández Padrón, jefe inmediato de César Sánchez. A través de un final ostentosamente antiformulario, donde no se da el nombre de la persona que verdaderamente hunde el cuchillo en el vientre de la víctima y solo se conoce el nombre del cabeza de turco al que el poder ha convertido en culpable. Explícitamente, se alude a la manipulación de los hechos para ajustarlos a las necesidades del sistema:

Lástima que esta vez la verdad lo alejara de la solución del caso. Al menos de la solución que le pedía su superior. [...] la muerte de Cuco Mondogo y todo lo que alrededor de ella se estaba moviendo, era el absurdo más grande al que se enfrentara en toda su vida. // Un absurdo que había funcionado a la perfección de un reloj para conducirle por un sendero cuyo destino era una mentira ciclópea disfrazada de verdad. Una historia oficial sólida e indestructible a la que no quedaba más remedio que someterse. (Lunar, 2013, p. 95)

En cuanto a los procedimientos paródicos relacionados con la evolución histórica del género policial en Cuba, la novela supone una extremada subversión de las formas del modelo policial revolucionario que en los años setenta y ochenta se produjo hegemónicamente bajo el sustento del Estado a través del concurso Aniversario del Triunfo de la Revolución. Los aspectos básicos de la narrativa revolucionaria (Fernández Pequeño, 1990; Rosell, 2000; Uxó, 2018) se construyen mediante la caracterización del detective como un grupo policial de eficacia, apariencia y moral incuestionadas, la presencia de un enemigo internacional antirrevolucionario integrado por gusanos (término asignado por el discurso oficial a los cubanos enemigos del comunismo) y fuerzas de los servicios de inteligencia estadounidense (la CIA), y, por último, la colaboración necesaria del pueblo por medio de los representantes locales de los Centros de Defensa de la Revolución (CDR), siempre atentos a defender la isla frente al enemigo exterior. De esta manera, como la PNR y las Fuerzas Armadas de la Revolución (FAR), los ciudadanos son revestidos de una ideología incorruptible fundamentada en el compromiso socialista más allá de cualquier otra creencia o lazo.

En relación al primer aspecto, la narración de la acción de un equipo policial coordinado e incorruptible, como se ha mencionado, es reconfigurada paródicamente en la rivalidad entre el capitán César y el teniente Lázaro Andrés que se expresa en los recurrentes deseos del capitán por aplastar a quien considera grotesco, amanerado, presuntuoso y, en especial, un molesto peligro para el mantenimiento de su em- 
pleo y de su liderazgo en la Unidad Policial. Como el lector y el protagonista descubren, tras un acelerado y violento segundo careo con los testigos del caso, el teniente es parte del plan del coronel Hernández Padrón para expulsar al oficial afrocubano de su cargo, a la par que para mantener el creciente negocio de turismo sexual de La Ciudad.

Tampoco existe la presencia de un enemigo contrarrevolucionario nacional o internacional dispuesto a sabotear los progresos de la Revolución en marcha: ni reaccionarios batistianos ni agentes de la CIA amenazan el devenir revolucionario. El verdadero enemigo del pueblo cubano son las fuerzas del Estado, en concreto, los cuadros policiales y militares que, desmintiendo la propaganda gubernamental, perpetúan las tildadas como peores lacras del periodo prerrevolucionario: el racismo y la prostitución, además de la violencia sistémica y la desigualdad social.

Finalmente, la representación de los ciudadanos dispuestos a colaborar en la resolución del enigma se aleja de los cauces habituales de la creación policial revolucionaria. En esta última, la ayuda procede de idílicas entrevistas con acogedoras ancianas presidentas del CDR de la zona o con vecinos siempre alerta y ávidos por participar en las actividades de voluntariado. Muy distintamente, en Proyecto en negro, los suministradores de la información durante las pesquisas del capitán César y el teniente Lázaro Andrés son, entre otros, Lola Bataola, una anciana presidenta del CDR de su zona y prostituta aún en activo, y Mami la Ambulancia, un homosexual perseguido por serlo que es obligado a desempeñarse como confidente a cambio de la libertad. La mísera marginalidad de estos personajes provoca el rechazo en el policía protagonista, mientras que la arbitrariedad abusiva de los agentes genera el miedo y la desconfianza en los santaclareños.

\section{LA INTERTEXTUALIDAD: REDES, ORGANICIDAD Y REESCRITURAS}

Por otra parte, la intertextualidad es un recurso fundamental en Proyecto en negro. El propio personaje de Cuco Mondongo es parte de la red que se establece entre los autores del género policial cubano. El lúbrico pordiosero, que utiliza su carretilla para transportar a sus embriagadas víctimas al cementerio y sodomizarlas sobre las lápidas -con o sin consentimiento- aprovechando que el efecto del alcohol los ha dejado indefensos y postrados sobre las aceras en mitad de la noche, es invención de Mario Brito, autor de La tierra del Cebú, publicada por la editorial cubana Oriente en 2011 y por la editorial española Atmósfera Literaria al año siguiente. En esta última se editan Proyecto en negro y otros títulos como parte de la producción neopolicial de Cuba. A la narración de Brito, también pertenece el pueblo Ríos de Primavera, aislada y pequeña localidad a la que el capitán César rehúsa volver pase lo 
que pase y donde fue destinado tras su fracaso en la investigación en torno a la desaparición de una turista extranjera.

Este pasaje de la vida del policía de Proyecto en negro forma parte del conjunto de intertextualidades. En este caso, se trata de una referencia intratextual, a modo de extensa síntesis del argumento, que conecta la novela analizada con Polvo en el viento (2005) (llamada en su edición española Mundo de sombras [2011]), igualmente protagonizada por el policía César Sánchez. En dicho título, el caso criminal gira en torno a la búsqueda de una joven italiana, Bianca Rossana Micussi, cuyo paradero queda sin resolver. Además, no se puede obviar que, aunque algo desfigurado y con carácter muy secundario, la figura de César está presente en la trilogía de Leo Martín, El barrio en llama, donde aparece como el oficial superior del centro policial donde trabaja Martín. Estas y otras conexiones entre personajes y referentes espaciales de las diferentes obras permiten identificar La Ciudad antonomástica de Proyecto en negro con la explicitada Santa Clara de la trilogía o de Polvo en el viento. Así, esta ciudad de provincias de referente real en la toponimia cubana es recreada literariamente como un espacio criminal característicamente integrado en las directrices de la fórmula neopolicial hispanoamericana, en el que la violencia y la depravación que embarran la urbe se configuran como reflejo de la degradación social y la corrupción gubernamental.

La intertextualidad también se pone en función de la reescritura del relato policial revolucionario. Lunar no deja de acudir al intertexto en forma de alusión paródica, al presentar al lector las delirantes elucubraciones de César en torno a la muerte del indigente, que oscilan entre culpabilizar a integrantes del lumpen local y responsabilizar a las consabidas agencias internacionales de inteligencia:

Si aquella noche Cuco Mondongo no recogió a ningún turista, entonces es posible que quien lo haya matado sea un nacional. Otro pordiosero como él. [...] // Pero esto es solo una hipótesis. No tengo ni una sola prueba de que fuera de esa manera. [...] ¿Y si es un agente de la CIA? ¿Otra más de las tantas agresiones del enemigo? ¿Otro intento por destruir nuestra economía ahuyentando el turismo? Si dejo pasar un caso en el que esté metida la mano de la CIA y la mafia anticubana de Miami, entonces sí que el coronel Hernández Padrón me destruye para siempre [...]. (Lunar, 2013, pp. 60-61)

\section{SÁTIRA SOCIAL Y POLÍTICA: SANTA CLARA COMO ESPACIO DE LA DISCRIMINACIÓN}

A lo largo de la narración, la violencia del espacio urbano santaclareño deja de lado el crimen esporádico del asesinato y se materializa en una asfixiante atmósfera de discriminación continuada y brutal. La desigualdad económica, el racismo, el machismo, la homofobia y la violencia de género, en la novela, son conductas habitualmente practicadas por la sociedad en general y por las fuerzas policiales en parti- 
cular. La saturación de la convivencia provocada por estas vías de segregación revela el mantenimiento de una sociedad estratificada, heteropatriarcal y de supremacía blanca. El modo radical en que este retrato de La Ciudad ficcional se opone a las premisas igualitarias socialistas instauradas por la Revolución cubana que sirve como referente extraliterario confiere a Proyecto en negro una fuerte carga satírica atravesada de un humor negro proveniente de la crudeza del lenguaje y del retrato grotesco de unos personajes amorales e hipersexualizados.

Rosa María Díez Cobo (2006) traza los rasgos de una escritura satírica contemporánea diferenciada de la sátira formal -caracterizada por la condena moralista de actitudes marginales desde un discurso hegemónico- y de la sátira menipea -cuya subversión carnavalesca de los Estados e instituciones represores, según argumenta Michael Bajtín en su estudio epocal de la cultura popular (1965), se propone como salida utópica a la realidad focalizada. Para Díez Cobo, la sátira posmodernista hispanoamericana - de la cual señala como ejemplo más significativo El color del verano (1991), de Reinaldo Arenas- no busca transcender hacia la referencia exterior, sino que reconoce su exclusiva naturaleza textual. No obstante, señala la autora, esta nueva modalidad no renuncia a su potencialidad denunciante mediante el uso de diferentes estrategias discursivas que incluyen "humor, ironía, motivos carnavalescos, grotescos, alegoría, parodia, invectiva, humor negro, etc.” (Díez Cobos, 2006, p. 104).

Lunar, como se ha dicho, sitúa a sus personajes en La Ciudad. La convivencia de esta sociedad provinciana se encuentra intoxicada por algunas de las lacras que afectan a la mayoría de las comunidades contemporáneas y que pese al discurso oficial siguen perpetuándose. En este caso, existe una distorsión absoluta entre el discurso del Gobierno cubano extraliterario y la realidad ficcional que emana de los pensamientos y los actos de los protagonistas de Lunar. Este desajuste se ve exacerbado por el tono grotesco y el lenguaje agresivo del narrador y los propios personajes. Tales rasgos y el tono lúdico con que se narran determinadas situaciones esperpénticas generan un humor negro que da la espalda a soluciones utópicas y participan del escepticismo de la literatura posmoderna que, como advierte Díez Cobos, es consciente de su simple condición textual. La verdad perseguida como clímax paradigmático en el fin de la narración policial se describe en la propia diégesis como una imposibilidad, puesto que está sometida a todo tipo de versiones y manipulaciones: "No tenía más opción que la verdad. // Cuando tuviera la verdad, blanca y resplandeciente entre sus manos, ya sabría manejarla según sus necesidades. Como bien sabía hacer. Como se hace con cualquier hembra. La verdad es hembra y débil. La verdad es puta y embustera. // La verdad, blanca y maleable como el cuerpo de Idolidia" (Lunar, 2013, p. 39).

Este discurso lleno de elementos fuertemente carnalizados (a menudo, pornográficos), grotescos y absurdos aparece estrechamente conectado con el devenir del proceso revolucionario. La irreverente comicidad del discurso alcanza su máximo 
nivel cuando el narrador muestra las delirantes e interesadas perversiones a las que el pensamiento de César somete algunos de los hitos de la Revolución: la Zafra de los Diez Millones y la frase de Fidel Castro asociada al fracaso del objetivo propuesto -"convertir el revés en victoria"-, el materialismo dialéctico y el trabajo policial, la Perestroika y su propulsor Mijaíl Gorbachov, etc. Todos ellos son aspectos convertidos en irrisorios por medio de la machista, sexualizada, banal y atormentada mirada del deshonesto capitán, capaz de asimilar el lunar rojo del glande del occiso Cuco Mondongo con la marca de la piel que el político soviético tenía en la cabeza. Esta afinidad con el humor negro y la autoconciencia de la sátira posmoderna sobre su futilidad se plasman metaficcionalmente en la siguiente enumeración, que ilumina las circunstancias de un contexto donde la escritura ya no es la respuesta y un pueblo desencantado arroja los deshechos de la ideología a las alcantarillas: la cultura dejó de producir, los logros revolucionarios se olvidaron, la relación con el Bloque Socialista dio paso a la gran crisis del Periodo Especial en Tiempos de Paz, y el pueblo debió buscar sus propias soluciones alimenticias y habitacionales:

Los bomberos demoraron más de dos horas para achicar la inundación. Entonces se dedicaron a limpiar la cloaca. // Chancletas de plástico, suelas de zapatos, ripios de ropas... [...] Un cuero de chivo, las tripas de un puerco, la cabeza de una vaca ... rollos de alambre, trozos de cabillas [...] una máquina de escribir [...] una medalla de combatiente internacionalista, sellitos con la imagen de Lenin, Kim II Sung y Ho chi Minh. // Entonces fue que lo encontraron. Trabado en la boca del desagüe estaba el cadáver de Cuco Mondongo. (Lunar, 2013, p. 11) (La cursiva es mía)

A pesar de la aparente frivolidad del tratamiento humorístico y carnavalesco que imprime Lunar a su narración policiaca, el señalamiento de una parte de la realidad cubana es palpable en la obra. El lector puede percibir en la represión racista y machista existente en La Ciudad algunos de los objetivos fallidos, al menos en parte, del socialismo en Cuba. En este sentido, respecto a igualdad entre el hombre y la mujer se percibe un claro desajuste entre las pretensiones oficiales y los testimonios de los diferentes expertos y mujeres recogidos por Isabel Holgado Fernández en iNo es fácil! Mujeres cubanas y la crisis revolucionaria (2000). En esta recopilación crítica, junto al reconocimiento de las mejoras traídas por la Revolución, numerosas voces demandan medidas sociales, económicas y educativas propiciadoras de un verdadero equilibrio en las posibilidades y responsabilidades de ambos géneros. Del mismo modo, tras detallar el alcance positivo del proceso emancipador de la mujer cubana y el papel fundamental que esta juega en el devenir nacional, Salim Lamrani observa como "[m]acho, sexist and discriminatory behaviour, a legacy of five centuries of patriarchal society and its intrinsic cultural, ideological and psychological barriers, still persists in Cuba today and constitutes an obstacle to the full emancipation of women" (2016, pp. 114-115). 
En Proyecto en negro, el falocentrismo secular es recogido no solo por los alardes de desmedido machismo del protagonista - utiliza su falo como instrumento de sumisión, castigo y humillación de los sospechosos al final de los interrogatorios-, sino también por la voz narradora que se hace eco de los pensamientos de la mujer del capitán de la PNR, Regla, educada por su madre en el sometimiento a la voluntad del varón, la procreación y el cuidado de los hijos, y la satisfacción del deseo sexual masculino: "Ella obedeció sumisa, como debe ser la hembra. Abrió las piernas. Elevó la grupa. // Esa mañana los negritos llegarían tarde a la escuela" (Lunar, 2013, p. 134). Instituciones como la Federación de Mujeres Cubanas o la universidad son aludidas en relación a la acción y al pensamiento del protagonista, de manera que, en la novela, se menoscaba la eficacia del proceso emancipador femenino en el seno de la Revolución al ser aplastado por el peso del patriarcado, las necesidades económicas o la corrupción.

El racismo se proscribió en la isla con el triunfo revolucionario en 1959. Sin embargo, en el día a día, la sociedad cubana no se ha librado de este estigma, totalmente. ${ }^{4}$ Este es el aspecto discriminatorio expresado de modo más directo por la voz narradora para justificar el odio visceral que el superior siente hacia César Sánchez, a quien considera un subordinado indigno, especialmente, por el color de su piel. Esta fijación lleva a convertirlo en víctima de un complot que tiene como objeto despojarlo de su cargo en la PNR. Lunar satiriza la hipocresía de la sociedad cubana y de la propaganda oficial que siempre ha vindicado el fin del racismo y de la prostitución como dos de los logros de las políticas socialistas. Si en las primeras páginas, la coincidencia del año de nacimiento obtenida del expediente de Abelardo Cué, el individuo conocido como Cuco Mondongo, permite al teniente Lázaro Andrés identificar a su capitán con el indigente muerto, en el abierto desenlace, es el coronel quien convierte a César en el doble de Cuco, de manera que, bajo sus órdenes, el capitán pasa a sustituir al difunto sin techo en sus eróticas actividades nocturnas. La equivalencia está fundamentada en el desmedido racismo del alto cargo policial. Desde su mentalidad prejuiciada, que asigna a todos los afrocubanos un primitivismo y unas dimensiones del sexo arquetípicos, ambos sujetos son intercambiables.

La homofobia machista es otro de los elementos focalizados por la parodia satírica de Lunar. El pensamiento del capitán se convierte en ejemplo de la perspec-

\footnotetext{
${ }^{4}$ Rodríguez Espina y Molina Ruiz (2006) analizan la evolución de este aspecto a partir de la Revolución. Su estudio, si bien señala los avances positivos logrados hasta el momento y la esperanza de la población en un futuro aún mejor, concluye que las "desigualdades raciales persisten en Cuba, y se han hecho más visibles principalmente a partir de la crisis económica de los años 90 . Se trata de la consecuencia de la funcionalización de formas de racismo que han permanecido agazapadas en la subjetividad de muchas personas. Es una forma de racismo sociológico que, en condiciones de apertura de espacios competitivos y revalorización simbólica y real de determinados sectores económicos, encuentra capacidad para generar verdaderas desigualdades. Entre otros aspectos, en las representaciones raciales predomina una evaluación negativa de los negros y una positiva de los blancos, lo que configura una de las barreras fundamentales que limita la movilidad de los negros hacia los sectores más ventajosos". (p. 53)
} 
tiva de un hombre que se autoconceptúa como macho y que rechaza a los homosexuales. Su hipermasculinidad (Ramírez y García Toro, 2002) se construye sobre la violencia sobre otras masculinidades subordinadas de personajes que, aunque tratan de enfrentarlo, son sometidos por el poder policial represor y heterocéntrico. Al despreciarlos, los percibe como marginales a los que convierte en objetivo de sus interrogatorios y de sus sospechas. En consonancia con ello y por encima de otras evidencias, el argumento más poderoso que cree tener contra el teniente Lázaro es la constatación de su homosexualidad.

En definitiva, Lunar construye en Proyecto en negro una narración neopolicial donde la parodia y el intertexto se convierten en dos de los rasgos más sobresalientes. Ambas estrategias funcionan como piezas fundamentales de la sátira social y la reformulación de la narrativa policial clásica y del relato policial revolucionario cubano que la escritura ofrece al lector. Como sátira social el texto se carga de un humor negro -lenguaje de gran crudeza, tratamiento hipersexualizado de los personajes y de sus acciones, recurrencia de elementos grotescos y absurdos- que busca llamar la atención sobre el desequilibrio entre la violenta discriminación y represión que asfixia la sociedad de La Ciudad novelesca, y un supuesto discurso oficial extraliterario, que se muestra, de este modo, en su carácter de idealización. 


\section{BIBLIOGRAFÍA}

Adriaensen, B., y Grinberg Pla, V. (2012). Narrativas del crimen en América Latina: transformaciones y transculturaciones del policial. Berlín: LIT Verlag.

Argüelles, J.D. (1990). Entrevista con Paco Ignacio Taibo II. El policiaco mexicano: un género hecho con autor y terquedad. Tierra adentro, 49, 13-15.

Borges, J.L. (1944). Ficciones. Buenos Aires: Sur.

Brito Fuentes, M. (2011). La tierra del cebú. Santiago de Cuba: Editorial Oriente.

Díez Cobo, R.M. (2006). Nueva sátira en la ficción postmodernista de las Américas. Valencia: Universitat de València.

Espina Prieto, R., y Rodríguez Ruiz, P. (2006). Raza y desigualdad en la Cuba actual. Temas, 45, 44-54.

Fernández Pequeño, J.M. (1994). Cuba: la narrativa policial entre el querer y el poder (1973-1988). Santiago de Cuba: Oriente.

García Talaván, P. (2014). La novela neopolicial latinoamericana: una revuelta ético-estética del género. Cuadernos Americanos, 2 (148), 63-85.

Gewecke, F. (2010). La "nueva" novela policial cubana: Leonardo Padura Fuentes, Amir Valle, Lorenzo Lunar. En A. Gremels, y R. Spiller, Cuba: la revolución revis(it)ada (171-190). Tübingen: Narr Verlag.

Giardinelli, M. (1996). El género negro: ensayos sobre literatura policial. Córdoba: Op Oloop.

Holgado Fernández, I. (2000). ¡No es fácil! Mujeres cubanas y la crisis revolucionaria. Barcelona: Icaria.

Lamrani, S. (2016). Women in Cuba: the Emancipatory Revolution. International Journal of Cuban Studies, 8 (1), 109-116.

Noguerol Jiménez, F. (2006). Neopolicial latinoamericano: el triunfo del asesino. Ciberletras: revista de crítica literaria y de cultura, 15. Recuperado de http://www.lehman.edu/faculty/ guinazu/ciberletras/v15/noguerol.html.

Padura Fuentes, L. (2000). Modernidad, posmodernidad y novela policial. La Habana: Unión.

Ramírez, R.L., García Toro, V.I. (2002). Masculinidad hegemónica, sexualidad y transgresión. Centro Journal, 14 (1), 5-25.

Rosell, S. (2000). La (re)formulación del policial cubano: la tetralogía de Leonardo Padura Fuentes. Hispanic Journal, 21 (2), 447-458.

Sánchez Zapatero, J., y Martín Escribà, À. (2014). Revolución, desencanto y crítico: la novela criminal cubana. Cuadernos de Investigación Filológica, 40, 171-189.

Sklodowska, E. (1991). La parodia en la nueva novela hispanoamericana (1960-1985). Amsterdam-Philadelphia: John Benjamins Publishing Company.

Taibo II, P.I. (1987). La "otra" novela policiaca. Los Cuadernos del Norte, 41, 36-41.

Uxó, C. (2016). Hacia una nueva poética del policial cubano: la trilogía de Leo Martín, de Lorenzo Lunar Cardedo. Altre Modernità, 15, 257-269. DOI: https://doi.org/10.13130/2035-7680/7189.

Uxó, C. (2018). El concurso Aniversario del Triunfo de la Revolución. En E. Gallardo-Saborido, J. Gómez-de-Tejada, y D. Puñales-Alpízar (eds.), Asedios al caimán letrado: literatura y poder en la Revolución cubana (129-146). Praha: Universidad Carolina, Karolinum. 